\title{
When Disaster Risk Management Systems Fail: The Case of Cyclone Idai in Chimanimani District, Zimbabwe
}

\author{
Edson Munsaka ${ }^{1,2}$ - Chipo Mudavanhu ${ }^{3}$ Lucy Sakala $^{3}$ Pepukai Manjeru ${ }^{4}$. \\ Diego Matsvange ${ }^{5}$
}

Accepted: 31 August 2021/Published online: 12 October 2021

(C) The Author(s) 2021

\begin{abstract}
On 14 March 2019, Zimbabwe was hit by Cyclone Idai, leaving immeasurable destruction of unprecedented magnitude in its wake. In Chimanimani District, many lives were lost, many people were reported missing, and others were displaced. The question that immediately comes to mind is: Was the country prepared to manage the Cyclone Idai disaster? Reflecting on the community experiences, the purpose of this research was to interrogate the strength of the disaster risk reduction legislation and institutions in Zimbabwe in the face of meteorological hazards. The research also evaluated the extent of the impact Cyclone Idai had on the Chimanimani communities and the factors that increased the vulnerability to the cyclone. A mixed method approach that involved 1180 participants was used. The study found that disaster risk management legislation and institutions in Zimbabwe are weak. Cyclone Idai resulted in the loss of many human lives, loss of livelihoods, and massive damage to infrastructure. The cyclone exposed capacity and policy gaps in Zimbabwe's disaster risk management system. The study makes a number of recommendations, including strengthening disaster legislation and policy, and disaster risk governance. Given the communities' response
\end{abstract}

Edson Munsaka

emunsaka6911@gmail.com

1 Institute of Development Studies, National University of Science and Technology, Bulawayo, Zimbabwe

2 Faculty of Humanities, University of Johannesburg, Johannesburg, South Africa

3 Bindura University of Science Education, Bindura, Zimbabwe

4 Midlands State University, Gweru, Zimbabwe

5 DanChurch Aid (DCA), Bulawayo, Zimbabwe to the disaster occurrence, the study also recommends strengthening social capital.

Keywords Cyclone disasters - Disaster management policies $\cdot$ Early warning systems $\cdot$ Zimbabwe

\section{Introduction}

Climate change is affecting societies in unprecedented ways across the globe. Analyzing 750 empirical estimates, Klomp and Valckx (2014) show the negative effects of climate change on economic growth per capita, and Felbermayr and Gröschl (2014) state that climate change effects reduce per capita gross domestic product (GDP) by up to $6.8 \%$ in the year they occur. According to Munich Re (2018), tropical cyclones were responsible for nearly half of all natural hazard-related disaster losses worldwide from 1980 to 2018, with damage amounting to an aggregate of USD 2111 billion. Globally they are among the most destructive natural hazards (Kunze 2021). The African continent, particularly south of the Sahara, has not been spared either. If anything, due to their geographical location, most of the countries are vulnerable to natural hazardrelated disasters (Klomp and Valckx 2014). Climate change is estimated to have influenced the rising of temperatures in Mozambique by $0.6{ }^{\circ} \mathrm{C}$ between 1960 and 2009, while average rainfall totals have declined over the same period (Arndt et al. 2012). In March and April 2019, two consecutive major cyclones struck Mozambique, affecting more that 1.7 million people, with damages and losses amounting to USD 3 billion, and an estimated USD 3.4 billion total cost for recovery and reconstruction (Government of Mozambique 2019). 
The colossal devastation and displacement brought by cyclones has not spared Zimbabwe, which continues to experience natural hazards such as tropical cyclones, droughts, and floods, and at times the hazards generate disasters. Such hazards are expected to increase both in frequency and intensity due to climate change, with cyclone-induced flooding one of the most common and devastating events, causing nearly half of all victims of natural hazards (Rana and Routray 2018; Mhlanga et al. 2019). During 2000 Cyclone Eline, floods claimed more than 700 lives, left more than 500,000 people homeless, and caused USD 1 billion in infrastructural damage in Zimbabwe and Mozambique combined (Wamukonya and Rukato 2001). The most recent tropical cyclones-2017 Cyclone Dineo and 2019 Cyclone Idai, that hit Zimbabwe also caused flooding and left a trail of destruction in communities, creating socioeconomic challenges among the people.

Chimanimani District experienced destructive Cyclone Idai from 14 to 17 March 2019. The cyclone caused high winds and heavy precipitation in the Chimanimani District and heavily impacted at least half of its total population of about 135,000 (2012 Census) in 15 of the 23 wards (UNICEF 2019). The cyclone triggered landslides, as well as riverine and flash floods, leading to deaths and destruction of livelihoods and properties. As reported by the Chimanimani District Development Coordinator, Cyclone Idai claimed about 300 lives, more than 325 people were reported missing, and approximately 4000 people were displaced (Matsvange et al. 2020).

The occurrence of Cyclone Idai exposed capacity and policy gaps in Zimbabwe's disaster risk management (DRM) system. The magnitude of this disaster exposed the deficiencies in the national and local disaster risk management systems, as well as other community factors that increase household vulnerability to hazards. Therefore, the purpose of this study was to understand how weak institutions and inadequate disaster legislation can combine to exacerbate natural hazards in vulnerable communities located in disaster-prone areas such as mountainous areas. It specifically looked at how weak national disaster legislation in Zimbabwe created an opportunity for Cyclone Idai to affect people the way it did in the mountainous Chimanimani District.

\section{Description of the Study Area}

The study was carried out in Chimanimani District, Manicaland Province, in eastern Zimbabwe on the border with Mozambique. The district is divided into 23 wards. The specific wards that took part in the study are Ward 10 (Chikukwa), Ward 11 (Martin), Ward 12 (Tilbury), Ward
13 (Nyahode), Ward 15 (Chimanimani), Ward 16 (Gwindingwi), Ward 17 (Biriri), and Ward 21 (Ngorima A). Ngangu located in Ward 15 and Kopa in Ward 21 were the most affected settlements by Cyclone Idai.

The climate in Chimanimani is warm and temperate. The mountainous eastern areas include the second-highest peak in Zimbabwe Mount Binga, which rises to $2440 \mathrm{~m}$ above sea level and experiences high rainfall of up to 1,400 mm per year (Government of Zimbabwe 2016; Chingombe and Musarandega 2021). The area is prone to tropical cyclones as it lies in the overland path of the cyclones from Mozambique and the Indian Ocean (DCP 2013). The topography is extremely rugged, with ranges of peaks and ravines that cause resistance to the movement of tropical cyclones. As a result, most of the strength of Cyclone Idai was directed at the eastern highlands of Chimanimani, concentrating heavy rains in the district. The soils have high agricultural productivity, a characteristic of agroecological Region 1 (Musasa et al. 2015; Chingombe and Musarandega 2021). The soil particles are well graded and consolidated, making them less vulnerable to erosion, thereby enabling farmers to plough and grow crops on slopes and in hilly places.

The shortage of habitable land has forced some communities to settle on dangerously steep slopes and along waterways that are susceptible to landslides. The local authorities have also continued to create settlements in visibly risky and vulnerable spaces. Logging, residential and infrastructure development, and other activities continue to expand on slopes highly prone to landslides. The mountains have lost significant tree cover due to illegal settlers rampantly uprooting, cutting, and burning trees to prepare farmland. According to the assessment by the Environmental Management Agency (EMA) in 2019, affected areas by water were mainly located in floodplains, along waterways, and on steep slopes. Inadequate watershed management in the district is the leading threat to biodiversity, with low river volumes, poor forest cover, rangeland degradation, and increasing vulnerability to flooding and landslides. Another contributor to reduced water volumes appears to be exotic tree plantations enclosing river sources. The effects of degrading land are observed in soil compaction, increased run-off, loss of soil fertility, and decrease in vegetation cover. There is also apparent stream bank cultivation around many rivers and river sources.

\section{Conceptual Framework}

Vulnerability is a concept that has been used in different research fields, but there is no consensus on its meaning and definitions (Hufschmidt 2011). It can be described as 
the diminished capacity of an individual or group to anticipate, cope with, resist, and recover from the impact of a natural or man-made hazard (Kasi and Saha 2019). It is also possible to view vulnerability as an internal risk factor of the subject or a system that is exposed to a hazard and corresponds to its intrinsic tendency to be affected, or susceptible to damage. Emrich and Cutter (2011) concur with Cardona (2003) who argued that vulnerability represents the physical, economic, and/or social susceptibility of a community to damage in the case of a threatening circumstance of natural or anthropogenic origin. However, vulnerability is most often associated with poverty, though it can also arise when people are isolated, insecure, and defenceless in the face of risk, shock, or stress. So, in a general sense, vulnerability can be defined as the inability of a system to withstand the perturbations of external stressors or withstand the effects of a hostile environment (Ciurean et al. 2013). As Chapungu (2020) noted regarding the impact of Cyclone Idai, the huge devastation and displacement brought about by the cyclone underline the vulnerability of individuals and communities to climate change-related disasters. The location of the communities of Chimanimani made them susceptible to all the characteristics that define vulnerability.

Risk can be described as a combination of two factors: likelihood and consequence. The two factors can be described both qualitatively and quantitatively (Askman et al. 2018), and in several ways depending on the aim and context (Coppola 2011). However, as Askman et al. (2018) argued, risk consists of more than just its technical aspects. Its research should include the subjective values that serve a purpose in different situations. Renn (1998), Slovic (2001), and Coppola (2011) emphasized the importance of risk awareness and risk perception. People differ in their vulnerability to risk as a result of their social group, gender, ethnic or other identity, age, and other factors. It is the failure to recognize risk and the impaired risk perception of such individuals or communities that make them settle in vulnerable spaces. However, their vulnerability status also has an influence. Therefore, the failure to have strong DRM legislation and implementing institutions further exacerbates the level of risk to the hazard, as was the case in Chimanimani District in Zimbabwe. Increased levels of vulnerability further increase the impact once a hazard strikes, creating a vicious cycle of vulnerability (Mavhura 2017).

\section{Methodology}

A pragmatic research approach was used. It involved a mixed method approach that combined qualitative and quantitative methods. The main emphasis of a pragmatic approach is the use of external, multiple realities and a focus on the best choice to answer a research problem (Saunders et al. 2019). Both subjective and objective perspectives were applied practically to integrate the views needed to assist in the data interpretation (Hallebone and Priest 2009; Lincoln et al. 2011). Participatory action research (PAR) principles guided the execution of the research process. Participatory action research involves a cyclic process of research, reflection, and action (Marshall and Rossman 2006) that "offers a critique of, and challenge to, dominant positivist social science research as the only legitimate and valid source of knowledge" (Maguire 1987, p. 10). The researchers and participants involved in the study worked together to understand the problematic Cyclone Idai situation that occurred in Chimanimani District in Zimbabwe in the context of the existing disaster legislation in the country.

The data collection process followed a multistage sampling technique, one that involves two or more stages of random sampling based on the hierarchical structure of natural clusters within the population. Clusters are natural groupings of people within a population-for example, households (Sedgwick 2015). Purposive sampling was used to select eight out of the 15 affected wards in the district. The wards selected were Chikukwa, Ngorima A, Nyahode, Chimanimani urban, Gwindingwi Martin, Biriri, and Tilbury. There were about 11,610 households in the selected wards. A $10 \%$ sample per ward was considered and 1,161 households were selected through simple random sampling. Table 1 presents the total sample size, including the key informants who were also purposively selected.

Stakeholders comprising local households, local community leadership, heads of government departments from Chimanimani, and university researchers met at Biriri on

Table 1 Total number of research participants in the study on the impact of 2019 Cyclone Idai in Chimanimani District, Manicaland Province, Zimbabwe

\begin{tabular}{lll}
\hline Ward no. & Ward name & No. of participants per ward \\
\hline Ward 10 & Chikukwa & 70 \\
Ward 11 & Martin & 46 \\
Ward 12 & Tilbury & 180 \\
Ward 13 & Nyahode & 267 \\
Ward 15 & Chimanimani & 160 \\
& $\quad$ urban & \\
Ward 16 & Gwindingwi & 132 \\
Ward 17 & Biriri & 132 \\
Ward 21 & Ngorima A & 174 \\
Key informants & & 19 \\
Total & & 1180 \\
interviewed & & \\
\hline
\end{tabular}


21 December 2019. Together, the various teams came up with a set of questions that developed into the main questionnaire. The enumerators were also involved in the development of the questionnaire. The same procedure was followed in creating the interview questions for the semistructured interviews to be conducted with the key informants.

After the questionnaire was finalized, it was loaded into KOBO collect, a mobile software application used to collect data digitally. The enumerators were trained in the use of KOBO and used digital tablets to collect household data. The use of KOBO collect allows the delivery of real-time data, automatic collection of GPS readings to cater for accuracy, and automatic timing of interviews.

Both the household tool and the interview guide were pretested to see whether the enumerators had understood the process and to check whether there were questions that required revision. All questions that were ambiguous or difficult to understand were improved for the final tool. When the researchers were satisfied with the competence of the enumerators and the clarity of the questions to be asked, the enumerators were sent to collect data from the households. The data collection progress was monitored daily, which allowed quality assessment of the data. The information that was collected ranged from household demographics, awareness and knowledge of climate hazards, impact of the cyclone, and governance to early warning systems. People who participated in pretesting were excluded from participating in the final research study. Thirty enumerators collected data in seven working days. The researchers monitored the data collection process, with data uploaded and updated daily on the KOBO server.

\subsection{Data Collection Methods and Tools}

The study adopted both quantitative and qualitative methods. The quantitative data were collected using the household survey. The qualitative research methods used were semistructured interviews with the key informants and focus group discussions (FGDs).

\subsubsection{Quantitative Research Tools}

The study used a structured household questionnaire survey to interview 1161 households. The questionnaire was administered to household heads, but in their absence, the most senior person in the household was interviewed. One person per household took part in the household survey. Before the start of the interviews, respondents were briefed on the purpose of the study and were informed that their participation in the study was voluntary. Respondents were assured that their identity would not be disclosed to any third party. The data were collected by 30 trained enumerators supervised by eight supervisors who were also enumerators, using computer assisted interviews. The questionnaires collected data on 21 context-specific variables that increase social vulnerability to floods, as well as data on exposure, and biophysical vulnerability elements and indicators. They also addressed cyclone early warning systems, preparedness, and capacities for mitigation, coping, and adaptation. Each interview was approximately 45 min long.

\subsubsection{Qualitative Research Tools}

A total of eight focus group discussions (FGDs) were conducted in the selected wards. Village heads assisted the researchers in selecting participants for the FGDs from the household survey sample, based on their availability and willingness to participate. The focus groups were fairly gender balanced, and each FGD had between 10 and 12 participants. The participants discussed the causes of the cyclone, magnitude and impact, exposure, vulnerability conditions, the coping mechanisms, and the challenges they faced during and after the cyclone.

In addition to the FGDs, 19 semistructured interviews were administered to 19 key informants: the provincial and district development coordinators, a rural district council officer, two chiefs, headmen, and village heads respectively, as well as an officer from the Social Welfare Services Department, Ministry of Women's Affairs, Environmental Management Agency, and Ministry of Youth Empowerment, the district schools inspector, three representatives from the nongovernmental organization (NGO) sector, and two emergence shelter supervisors. The use of semistructured interviews allowed the researchers to generate descriptions of the Cyclone Idai affected communities, complementing the data generated through the household surveys and the FGDs. The quantitative data were analyzed using SPSS 21 . The data collected were then cleaned and analyzed for both descriptive and inferential statistics. The qualitative data were analyzed following the dictates of thematic analysis.

\subsection{Ethical Considerations}

The project was funded under the TSURO Trust in Chimanimani. The research clearance was obtained from the TSURO Trust. The research team also got permission to undertake the study from the provincial and district development coordinators, ward councillors, and village heads. The research aim and objectives were clearly explained to all the participants and they gave their oral consent. At the beginning of each discussion the participants were given information concerning the voluntariness 
of their participation and the confidentiality and anonymity of what they were going to say. The assessment team also engaged local partners as enumerators who were aware of gender and cultural norms and to inform on local governance issues. The study protocol was subjected to an ethical assessment by the Institutional Research Ethics Committee at the National University of Science and Technology (NUST), Bindura University of Science Education, and Midlands State University.

\section{Findings}

The results are presented in three sections, structured into the categories that emerged from the analysis. Section 5.1 concerns the issue of managing meteorological hazards. Cyclones are one such a hazard. Section 5.2 focuses on the socioeconomic impacts of Cyclone Idai on the communities of Chimanimani. Section 5.3 presents the factors that contributed to household vulnerability to Cyclone Idai in the study area.

\subsection{Disaster Risk Management Policies in Managing Cyclone Idai}

The Cyclone Idai disaster exposed policy gaps in Zimbabwe's disaster risk management system. The interviews with the key informants revealed that Chimanimani District, like any other district in the country, observed a number of policies. Some of those policies were national while others were local instruments. The national policies identified included the Constitution of Zimbabwe (Amendment No. 20 of 2013); the Traditional Leaders Act (Chapter 29:17); the Rural District Councils Act (Chapter 29:13); the Provincial Councils and Administration Act (Chapter 29:11); the Housing Standards Control Act (Chapter 29:08), and the Civil Protection Act (Chapter 10:06). The local policies were the Chimanimani Rural District Council Environment Policy (Resolution number C3090), and the Chimanimani District Climate Change Response and Watershed Management Policy (Resolution Number C3331). Some of these policies apply directly to disaster risk management while others apply indirectly. All these policies fit into the category of a DRM focused policy framework whose focus includes the reduction of people's vulnerability to hazards. The study revealed that at Kopa the area that was swept away was planned and allocated formally. Kopa is in Ngorima A (Ward 21). This is despite the fact that the land in question was vulnerable to flooding given its location. Field observational data showed that Kopa was located where three rivers joined. This was also noted by the headman of Ward 21:
When we were growing up we used to catch fish in the area where Kopa was built. The area was swampy and I was surprised that people were allocated land to build houses and government offices. The area is not suitable for human settlement.

The occurrence of Cyclone Idai further exposed policy failings in Zimbabwe's disaster risk management systems. Although the country has made significant strides in meeting the 2020 target, where the country is required to come up with comprehensive national and subnational disaster risk strategies aligned to the Sendai Framework for Disaster Risk Reduction 2015-2030, the disaster risk management legal and policy framework has not advanced fast enough. The rate of amending the Civil Protection Act of 1989 (Chapter 10:06) has been very slow to keep abreast with the prevailing international frameworks (Mavhura 2016). The key informants also revealed that the proposed Emergency Preparedness and Disaster Management Bill has remained a draft since 2011. Thus, the finalization of the DRM policy, legislation, and organizational structures based on the Constitution of Zimbabwe, the Sendai Framework, and relevant local experiences such as cyclones Idai and Deneo and those from other jurisdictions is becoming more urgent than ever.

Districts such as Chimanimani had their disaster preparedness plans in place because every district is expected to have in place disaster risk reduction (DRR) plans for effective response. However, one key informant interview revealed shortcomings:

We have very good disaster risk management plans but they have been shelved. We do not have the financial and human resources to implement our plans that include doing disaster drills and simulations. In the end, the government institutions are found wanting when it comes to disaster preparedness and response.

Therefore, in spite of the presence of these policies, the research found that government and local institutions were not prepared for Cyclone Idai in terms of alerting communities and training. Human resources, financial resources, infrastructure and equipment, and coordination were inadequate. When disaster risk management systems are riddled with shortcomings, the consequences of natural hazards overwhelm vulnerable communities, as happened to the communities of Chimanimani.

\subsection{Socioeconomic Impacts of Cyclone Idai in Chimanimani District}

Chimanimani District has a mixed economy. Primarily subsistence agriculture and small-scale horticulture 
production in the communal areas are the main economic activity. The narrative accounts of the cyclone survivors indicate that small-scale horticulture producers in Chimanimani lost pumps, pipes, and generators for individual small irrigated plots and crops-including sugar beans, potatoes, and bananas-due to Cyclone Idai. One of the FGD participants said: "We lost a lot of farming equipment especially in small irrigation areas. Crops were washed away. Fields have been degraded and our livelihoods are at risk. I am not sure if we are going to recover what we have lost to Cyclone Idai."

Participants recounted that, in addition to heavy physical, social, and economic losses, Cyclone Idai also killed people and livestock. Some people were reported missing. Figure 1 presents some of the impacts of Cyclone Idai on livelihoods.

Figure 1 shows that $63.1 \%$ of the research participants reported loss of land as the main challenge. The disaster also caused significant loss in grain (58.8\%), as well as loss of fields with trees/crops (58.1\%). Conflicts were mainly reported between the internally displaced (living in tents) and the surrounding communities over resources. The villagers felt that they used their resources to help the survivors before the external agencies intervened but they were neither compensated nor benefited from donor aid. The villagers argued that the donors actually created a gap between the survivors and the rest of the villagers:

Some of us were not directly affected by the cyclone but we helped our neighbors. We gave them food and shelter; but when the NGOs came they did not recognize us. Who will give us back the resources that we used to help the victims? I think we are not being treated fairly.

This view was corroborated by one of the survivors who was living in a tent;

We are facing a lot of challenges especially with the surrounding communities. People are vandalizing our property saying that we should be relocated to some place not in their neighborhood. We lost solar lights.

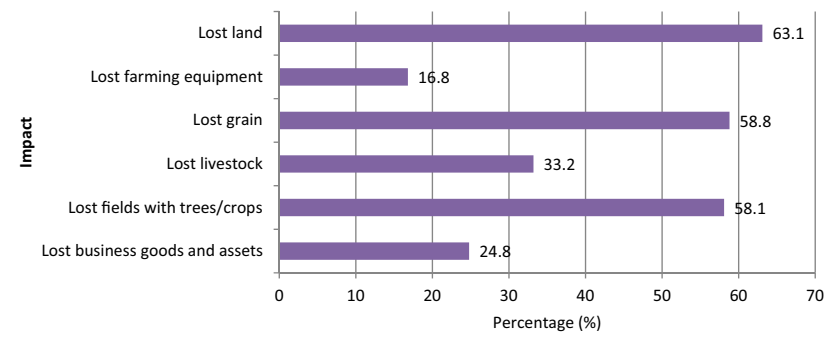

Fig. 1 Impacts of 2019 Cyclone Idai on livelihoods in the sample wards of Chimanimani District, Manicaland Province, Zimbabwe
The security fence was destroyed with some people threatening to burn our tents.

Cyclone Idai also impacted the communities of Chimanimani psychologically. Focus group discussions and key informant interviews indicated that some survivors remain haunted by the sights and screams of people they were unable to save from the floods. One woman during the FGD said:

Thanks to all well-wishers who are giving us food; we really appreciate but I can't eat not knowing where my children are. You expect me to eat and sleep when my two children are missing. All I need is to know where they are. I know that they are dead but my soul will have peace if they have a decent burial.

This was supported by another woman who lost her husband saying, "I am finding it very difficult to accept that my husband is reported missing. People die but they are buried properly. I don't know whether he was washed away or buried under rubble."

The events of the cyclone and its aftermath flash back through their minds. Women during the FGDs reported spending nights wide awake. They also reported poor eating habits, feelings of apprehension and worthlessness. Some people suffered from "survivor guilt." They reported feelings of self-defeat and self-loathing, a manifestation of post-traumatic stress disorder. Table 2 shows some of the psychosocial impacts identified during the 2020 fieldwork that continue to haunt people.

Other impacts of Cyclone Idai on Chimanimani communities were also noted during the research. Lack of privacy and safe spaces at emergency shelters in Ngangu and Kopa exposed women to sexual abuse. Participants highlighted that there was no lighting at the emergency shelters, which put women at risk. The study indicated that $40 \%$ of the participants reported cases of sexual exploitation and abuse of women and girls. However, no remedial action was taken by those in charge raising fears of victimization among those who dared to raise the alarm on the

Table 2 Social and psychosocial impacts of 2019 Cyclone Idai in Chimanimani District, Manicaland Province, Zimbabwe

\begin{tabular}{ll}
\hline Impact & $\%$ Affected \\
\hline Psychosocial & 43.5 \\
Missing members & 12.1 \\
Loss of property & 44.3 \\
Loss of arable land & 62.2 \\
Increasing conflict within the community & 61.0 \\
Loss of life & 9.4 \\
\hline
\end{tabular}


matter. The majority of the research participants $(92 \%)$ indicated that they were afraid of victimization. Exposure to sexual abuse of women and children was not limited to community spaces and strangers. Families living in tents were sharing a tent with the children, thereby exposing young children to sexual abuse. Lack of privacy for parents also triggered gender-based violence in emergency shelters. About $57.8 \%$ of the participants reported no preference given to pregnant and lactating women and girls in the provision of humanitarian aid, and $20.3 \%$ reported cases of gender discrimination with respect to access to relief aid. To a certain extent Cyclone Idai affected women and children more than men.

The feeling of powerlessness in the decision-making process and of insecurity reflected the social and psychological vulnerabilities of the affected women in the ravaged communities. Thus, women are at risk of falling into deeper poverty after Cyclone Idai, and this realization raises their social and psychological vulnerabilities. Most households in Chimanimani were convinced that women were now severely vulnerable to all forms of current and future shocks after Cyclone Idai. One woman during a FGD said:

Every day you have to wake up and look for food while men are roaming around. Sometimes they leave the family to look for a job which will bring no difference to the family. This has caused some misunderstandings in the home resulting in physical abuse by men. This is very common and we have lived to accept it.

\subsection{Factors Contributing to Household Vulnerability to Cyclone Idai}

Chimanimani represents the concentration of flood-related hazards that result from the multifaceted impacts of physical location compounded by climate change. The survey indicated that some houses were located along waterways and on floodplains. How these structures came to be erected in such risky spaces reflects policy failures as well as the incompetence of those in charge. Thus, the geographical location of households exposed communities to Cyclone Idai. Especially the Ngangu and Kopa residential areas in Chimanimani were in the path of the hazard. These residential areas and other physical infrastructure were at increased exposure and therefore vulnerable to flooding. The main structures that were at risk according to our research findings included houses, schools, health centers, business centers, and croplands located close to and along rivers in the study area. They were the victims of poor judgment and negligence or omission of duty by those in charge such as town planners and local authorities.
The capacity of local institutions to fulfil their obligation plays an important role in reducing community vulnerability to disasters. Education and knowledge of climate hazards in communities increase their capacity to prepare and respond to flooding. Where a community lacks such information their level of vulnerability tends to be high. Agricultural extension (Agritex) officers trained most people $(39.5 \%)$ on climate change hazards in Chimanimani, taking advantage of their positionality and relationship with the communities. Despite the training, the overall knowledge level on climate-related hazards among people in Chimanimani was low. Only $0.9 \%$ of the respondents were highly knowledgeable about climate change hazards, $46.3 \%$ had little knowledge, and $17.7 \%$ had no knowledge. This raises questions about the disaster risk knowledge levels of Agritex officers as facilitators or trainers in the disaster risk management subject matter. Low knowledge levels on climate hazards of communities increases their vulnerability to these hazards. The situation becomes worse when those in charge have no capacity to prepare the communities on how to respond to climate-related hazards. This further supports the need to build the capacity of vulnerable communities to assist them in coping with the hazards. Apart from education and training, 68\% of the households got information about the approach of Cyclone Idai from the media while more than $31 \%$ were caught unaware. This means a lot still needs to be done to get disaster information to people to prompt the required mitigating action. This might be the reason why people were seriously affected.

The attitude of community members influences disaster preparedness and response. More than two-thirds (68\%) of the respondents indicated that they received early warning information about the cyclone. Of those more than $85 \%$ shared the information with fellow community members. That people share information about impending danger is very encouraging. Surprisingly, however, only $36.7 \%$ of those informed took precautionary measures. The actions taken by people included moving to safer areas (12.6\%), staying indoors $(52.6 \%)$, and others $(2.1 \%)$ monitored reports on radio and television on what was safe to do. The majority of people thought the floods were not serious based on previous cyclone events. This might mean that the majority of the people who did not take action were not aware of what they were supposed to do, so training at the community level is needed on how people can mitigate the effects of disasters. This was exacerbated by lack of local disaster management committees. Lack of preparedness increases community vulnerability to disasters.

The presence and source of an early warning system or information on the impending danger has implications for the vulnerability status of the community concerned. A slight majority of the respondents $(53.7 \%)$ got information 
on the Meteorological Services Department (MSD) early warning about Cyclone Idai from radio and television, followed by fellow community members. The low number of people who got the information might be because in some wards there is low or no radio transmission. Other areas also have no cell phone / mobile network coverage, which explains the low number of people who received messages through cell phones. For a message to reach all people all possible methods of communication need to be used. Participants also highlighted other shortcomings with respect to communicating Cyclone Idai related information. More than $41 \%$ of the households said the information about the impending cyclone came too late. About $24 \%$ of the people said the information was inadequate to warn people of the impending danger, leaving them unable to act appropriately. More than $15 \%$ said the information was misleading and increased their exposure to the cyclone impact. The information was also affected by previous experiences with cyclones, like 2003 Cyclone Japhet and 2000 Cyclone Eline, which were less destructive. All these factors could have led to communities' lack of preparedness in the face of Cyclone Idai. Lack of disaster preparedness ultimately increases community vulnerability to hazards and also diminishes the risk perception of hazards.

In terms of assistance, only $3 \%$ of the respondents got early assistance from government agencies. This might mean that the government had no institutional structures in place to respond fast and adequately enough to disasters. Despite being aware of the impending danger through its early warning systems, the government did not deploy trained people to assist people who might be affected. Interviews with representatives of key government institutions indicated a lack of human and financial resources to prepare for emergencies. The government relied on humanitarian aid. The lack of human and financial resources further tends to increase community vulnerability to hazards such as Cyclone Idai in this context. This creates a vicious cycle of vulnerability to meteorological hazards like Cyclone Idai.

\section{Discussion}

The Zimbabwe disaster management system is guided by the Civil Protection Act (Chapter 10:06) of 1989 amended in 2001. Observation and commentary from various scholars indicate that Zimbabwe's disaster management system is more of a reactive system than a proactive one to any kind of disaster, be it slow/rapid onset or natural/human-induced. RINA (2019), Mudavanhu and Bongo (2015), and Mavhura and Collins (2017) agree that DRM activities in Zimbabwe are predominantly focused on response. Disaster risk management activities should focus on creating and enforcing mitigation measures.

The World Bank (2019) noted that the government of Zimbabwe declared an emergency on 16 March 2019 that activated a government-led response directed by the Department of Civil Protection (DCP), in coordination with humanitarian partners, the military, and subnational flood command centers. The response from the national level started to reach the affected communities after about four days to a week. There was a huge setback to the ability of the DCP to respond to the disaster in a timely and adequate manner because of the absence of reserved funds at all levels (RINA 2019). The absence of human resources such as the subaquatic and military units within communities at the district/ward level was a major contributor to the failure of the system to respond to the cyclone disaster. RINA (2019) noted that the national budget of Zimbabwe does not allocate direct support to DRM, thus the DCP like other departments gets its funding from the Treasury. This bureaucratic arrangement with centralized power delays the response rate to disasters (Mavhura 2016). The DCP requests funds from the Ministry of Finance and Economic Development (MoFED) contingency fund so that they can channel resources to the affected population. The lack of DRR investment undermines the disaster preparedness system.

According to Chatiza (2019) the survivors of Cyclone Idai were inadequately informed and supported. The DCP at both the district and the national levels failed to send out early warning messages to the affected communities in time for an adequate response. "The message about Cyclone Idai and how it was projected to affect Chimanimani did not effectively filter to the communities" (Chanza et al. 2020, p. 660). The World Bank (2019) confirmed that there was lack of community engagement with key actors in DRM with respect to awareness-raising and evacuation drill exercises. The DCP also had a gap in their risk perception as reflected by the reports the department made about the disaster. The weakness in the national disaster management system had also been observed by Manyena et al. (2013) as well as Chatiza (2019), a review of the experiences of, and response to, Cyclone Idai that shows that many agencies and institutions that play a role in Zimbabwe's disaster risk management system lack adequate technical, financial, and logistical capacities.

Furthermore, the current warning communication system is generic, with those issuing warnings not fully aware of the needs and priorities of vulnerable communities, and therefore not responsive to their needs (Gwimbi 2007). When emergency service committee meetings were held before the Cyclone Idai disaster, early warnings given were not accurate because they were not specific as to which areas were most vulnerable. This was supported by Chatiza 
(2019), who argued that the MSD's Cyclone Idai warnings generally lacked the detail necessary to allow the civil protection community to decide on immediate action in terms of evacuating people. RINA (2019) also noted that the reason behind the failure of early warning was the institutional lack of capacity of the Zimbabwe National Water Authority (ZINWA) and the MSD in terms of financial/human resources, technical expertise, facilities, and services. The lack of localized disaster preparedness is evident from the MSD, the army, the police, and the education and health sector, which led to the disaster (Chatiza 2019). Looking at the DRM system of Zimbabwe, schools should have been closed before the occurrence of the disaster in the affected areas. Also, the army lacked helicopters that could fly during extreme weather events. This is clear evidence that there was a lack of preparedness as the army could not immediately fly into affected areas, instead of having to wait for visibility to improve (Chatiza 2019). The police also was not prepared for search and rescue as they lacked sniffer dogs capable of detecting buried human bodies.

The lack of access to information related to early warnings, response strategies, and coping and adaptation mechanisms increases household vulnerability to disasters (IPCC 2012; Chapungu 2020). The survey report "Mitigating the Impact of Cyclone Disasters: Lessons from Cyclone Idai" reveals that "lack of information creates a barrier that heightens vulnerability, since the information does not effectively help the intended beneficiaries" (Chapungu 2020, p. 3). Access to information is critical for response behavior. Behavior change is vital when people get access to information because, as argued by IPCC (2012), it is not information per se that determines action, but how people interpret it in the context of their experiences, beliefs, and expectations. In the context of Chimanimani, the early warning information was not comprehensive enough to prompt any action. There was no recommendation on actions to take, so everyone was doing what they thought was appropriate. However, the government was also unaware of what action to take. Due to all these limitations, poor people are the most affected. They tend to have limited access to vital information, and yet information is critical for the reduction of vulnerability and increasing resilience (Torani et al. 2019). This explains why the poor are often hard-hit by disasters as they lack accessible information. They are also least equipped and prepared to cope with the impacts of disasters. Poor people have no resources, for example, to construct resilient houses that can withstand the impacts of disasters.

Most people got assistance first from fellow community members and NGOs. The role of government was not felt by the community members who are saying the major players were NGOs. However, this is not peculiar to
Chimanimani. Worldwide, it has been noted that most disaster survivors are pulled out of the rubble by community members (Kapucu 2008; Chanza et al. 2020). In view of this situation, there are calls to strengthen communities' capacity for coping with disasters (Musarurwa and Lunga 2012). Individuals should have a role to play, as they are the first responders. According to Bongo et al. (2013), if NGOs are the dominant players in times of hardships, then most communities are treading on the undesirable road of dependence. The authors went on to question what could happen to these communities if the NGOs suddenly withdrew from their area, or if their funding ran out. So, the most sustainable approach is to train communities to assist themselves and the government must also prioritize DRR in its budget. Bongo et al. (2013) noted the need to build on the traditionally existing extended family system and local community support systems as part of reducing vulnerability as well as building and strengthening resilience.

There is evidence that most injuries, damages, and deaths from disasters can be prevented. Disaster preparedness measures such as housing adjustments against risks can reduce the damage caused by disasters and improve recovery (Torani et al. 2019). Adherence to recommended standard building codes is a must. Low awareness and inadequate understanding of risk have a negative effect on people's readiness, response to hazard warnings, personal protection measures, and recovery. Disasters are reduced when people are well aware and have the motivation to create a culture of prevention and resilience to disaster. Disaster risk reduction legislation can reduce the destructive consequences of natural hazards by putting in place measures that reduce communities' vulnerabilities and build resilience.

\section{Conclusion}

How do weak national and localized DRM legislation and institutions combine to exacerbate natural hazards in mountainous areas? In what ways did the weak national disaster legislation in Zimbabwe create an opportunity for Cyclone Idai to affect people the way it did in the mountainous Chimanimani District? Our study shows that these are very complex questions to answer fully. However, our findings suggest the occurrence of Cyclone Idai exposed capacity and policy gaps in Zimbabwe's disaster risk governance system. For example, DRM policy is reactive and largely silent on mitigation trajectory. Although people got information about the impending disaster, they did not know how to use the information, because it was not properly packaged. The local institutions cannot deal with the vulnerabilities and risks posed by climate-related hazards. Cyclone Idai caused socioeconomic and 
environmental impacts in the district. Lack of effective DRM systems, lack of DRR training and awareness, population growth in mountainous areas, climate change, beliefs and attitudes, and settlements in dangerous locations like along waterways, lack of disaster preparedness at all levels, and household vulnerability attributes caused Chimanimani District to be susceptible to the damaging effects of Cyclone Idai. Besides highlighting the deficiencies in the disaster management system, this study also emphasized other community factors such as community attitudes that increased household vulnerability to hazards. There is a need to build the capacity of government institutions and traditional leaders and set up effective and efficient early warning systems in order to build community resilience.

Acknowledgments We are deeply grateful to the Tsuro Trust for providing the funding for the research. Furthermore, we express our special thanks to the residents of Chimanimani District who participated in the study. The research was conducted during their moment of sorrow due to Cyclone Idai. The anonymous reviewers, whose comments improved the quality of the article, are gratefully acknowledged.

Open Access This article is licensed under a Creative Commons Attribution 4.0 International License, which permits use, sharing, adaptation, distribution and reproduction in any medium or format, as long as you give appropriate credit to the original author(s) and the source, provide a link to the Creative Commons licence, and indicate if changes were made. The images or other third party material in this article are included in the article's Creative Commons licence, unless indicated otherwise in a credit line to the material. If material is not included in the article's Creative Commons licence and your intended use is not permitted by statutory regulation or exceeds the permitted use, you will need to obtain permission directly from the copyright holder. To view a copy of this licence, visit http://creativecommons. org/licenses/by/4.0/.

\section{References}

Arndt, C., P. Chinowsky, K. Strzepek, and J. Thurlow. 2012. Climate change, growth and infrastructure investment: The case of Mozambique. Review of Development Economics 16(3): 463-475.

Askman, J., O. Nilsson, and P. Becker. 2018. Why people live in flood-prone areas in Akuressa, Sri Lanka. International Journal of Disaster Risk Science 9(1): 143-156.

Bongo, P.P., P. Chipangura, M. Sithole, and F. Moyo. 2013. A rightsbased analysis of disaster risk reduction framework in Zimbabwe and its implications for policy and practice. Jàmbá: Journal of Disaster Risk Studies 5(2): Article a81.

Cardona, O.D. 2003. The need for rethinking the concepts of vulnerability and risk from a holistic perspective: A necessary review and criticism for effective risk management. In Mapping vulnerability: Disasters, development and people, vol 17, ed. G. Bankoff, G. Frerks, and D. Hilhorst. London: Earthscan.

Chanza, N., Q.P. Siyongwana, L. Williams-Bruinders, V. GunduJakarasi, C. Mudavanhu, B.V. Sithole, and A. Manyani. 2020. Closing the gaps in disaster management and response: Drawing on local experiences with Cyclone Idai in Chimanimani,
Zimbabwe. International Journal of Disaster Risk Science 11(5): 655-666.

Chapungu, L. 2020. Mitigating the impact of cyclone disasters: Lessons from Cyclone Idai. Johannesburg: South African Institute of International Affairs. https://media.africaportal.org/ documents/Chapungu_-_Final.pdf. Accessed 22 Mar 2021.

Chatiza, K. 2019. Cyclone Idai in Zimbabwe: An analysis of policy implications for post-disaster institutional development to strengthen disaster risk management. https://doi.org/10.21201/ 2019.5273. Accessed 17 Sept 2020.

Ciurean, R.L., D. Schröter, and T. Glade. 2013. Conceptual frameworks of vulnerability assessments for natural disasters reduction. In Approaches to disaster management-Examining the implications of hazards, emergencies and disasters, ed. J.P. Tiefenbacher, 1-32. London: IntechOpen Limited.

Chingombe, W., and H. Musarandega. 2021. Understanding the logic of climate change adaptation: Unpacking barriers to climate change adaptation by smallholder farmers in Chimanimani District, Zimbabwe. Sustainability 13(7): Article 3773.

Coppola, D.P. 2011. Introduction to international disaster management, 2nd edn. Burlington, MA: Butterworth-Heinemann.

DCP (Department of Civil Protection). 2013. Disaster risk management. Harare, Zimbabwe: DCP.

Emrich, C.T., and S.L. Cutter. 2011. Social vulnerability to climatesensitive hazards in the southern United States. Weather, Climate, and Society 3(3): 193-208.

Felbermayr, G., and J. Gröschl. 2014. Naturally negative: The growth effects of natural disasters. Journal of Development Economics 111: 92-106.

Government of Mozambique. 2019. Post disaster needs assessment. https://www.undp.org/content/undp/en/home/librarypage/crisisprevention-andrecovery/mozambique-cyclone-idai-post-disasterneeds-assessment-pdna-dna.html. Accessed 27 Mar 2021.

Government of Zimbabwe. 2016. Zimbabwe's National Climate Change Response Strategy. Harare, Zimbabwe: Government of Zimbabwe.

Gwimbi, P. 2007. The effectiveness of early warning systems for the reduction of flood disasters: Some experiences from cyclone induced floods in Zimbabwe. Journal of Sustainable Development in Africa 9(4): 152-169.

Hallebone, E., and J. Priest. 2009. Research paradigms. In Business and management research: Paradigms and practices, ed. E. Hallebone, and J. Priest, 43-70. Basingstoke, UK: Palgrave Macmillan.

Hufschmidt, G. 2011. A comparative analysis of several vulnerability concepts. Natural Hazards 58(2): 621-643.

IPCC (Intergovernmental Panel on Climate Change). 2012. Managing the risks of extreme events and disasters to advance climate change adaptation special report of the intergovernmental panel on climate change. Cambridge: Cambridge University Press.

Kapucu, N. 2008. Collaborative emergency management: Better community organising, better public preparedness and response. Disasters 32(2): 239-262.

Kasi, E., and A. Saha. 2019. Vulnerability and vulnerable groups of people. In The Palgrave Encyclopedia of global security studies, ed. S.N. Romaniuk, M. Thapa, and P. Marton, 1-7. Cham, Switzerland: Palgrave Macmillan.

Klomp, J., and K. Valckx. 2014. Natural disasters and economic growth: A meta-analysis. Global Environmental Change 26: 183-195.

Kunze, S. 2021. Unraveling the effects of tropical cyclones on economic sectors worldwide: Direct and indirect impacts. Environmental and Resource Economics 78: 545-569.

Lincoln, Y.S., S.A. Lynham, and E.G. Guba. 2011. Paradigmatic controversies, contradictions, and emerging confluences, revisited. In The Sage Handbook of qualitative research, $3 \mathrm{rd}$ edn, ed. 
N.K. Denzin, and Y.S. Lincoln, 97-128. Thousand Oaks, CA: Sage Publications.

Maguire, P. 1987. Doing participatory action research: A feminist approach. Amherst, MA: Center for International Education, University of Massachusetts-Amherst.

Manyena, S.B., E. Mavhura, C. Muzenda, and E. Mabaso. 2013. Disaster risk reduction legislations: Is there a move from events to processes?. Global Environmental Change 23: 1786-1794.

Marshall, C., and G. Rossman. 2006. Designing qualitative research, 4th edn. Thousand Oaks, CA: Sage.

Matsvange, D., C. Mudavanhu, P. Manjeru, M. Mbiriri, E. Munsaka, L. Sakala, and S. Mwacheza. 2020. Disaster risk reduction systems in the context of Cyclone Idai in Chimanimani. In Building resilience to natural disasters in populated African mountain ecosystems, vol 66-71, ed. D. Manatsa, K. Chatiza, T.D. Mushore, and C. Mudavanhu. Zimbabwe: Tsuro Trust, Harare.

Mavhura, E. 2016. Disaster legislation: A critical review of the Civil Protection Act of Zimbabwe. Natural Hazards 80(1): 605-621.

Mavhura, E. 2017. Building resilience to food insecurity in rural communities: Evidence from traditional institutions in Zimbabwe. Jàmbá: Journal of Disaster Risk Studies 9(1): Article a453.

Mavhura, E., and A. Collins. 2017. Flood vulnerability and relocation readiness in Zimbabwe. Disaster Prevention and Management 26(1): 41-54.

Mhlanga, C., T. Muzingili, and M. Mpambela. 2019. Natural disasters in Zimbabwe: The primer for social work intervention. African Journal of Social Work 9(1): 46-54.

Mudavanhu, C., and P.P. Bongo. 2015. Children's coping with natural disasters: Lessons from floods and droughts in Muzarabani District, Zimbabwe. Children and the Environment 25(3): 196-203.

Munich Re. 2018. NatCatSERVICE-Relevant natural loss events worldwide 1980-2018. https://www.munichre.com/en/solutions/ for-industry-clients/natcatservice.html. Accessed 2 Sept 2021.
Musarurwa, C., and W. Lunga. 2012. Climate change mitigation and adaptation: Threats and challenges to livelihoods in Zimbabwe. Asian Journal of Social Sciences and Humanities 1(2): 25-32.

Musasa, T.S., R. Musundire, M.B. Arnold, and M.S. Makuza. 2015. A preliminary study of the orange (citrus sinensis) fruit value-chain in Chimanimani Rural District, Zimbabwe. African Journal of Agricultural Research 10(35): 3507-3516.

Rana, I.A., and J.K. Routray. 2018. Multidimensional model for vulnerability assessment of urban flooding: An empirical study in Pakistan. International Journal of Disaster Risk Science 9(3): 359-375.

Renn, O. 1998. The role of risk perception for risk management. Reliability Engineering and System Safety 59(1): 49-62.

RINA (Zimbabwe Rapid Impact Needs Assessment). 2019. May 2019. In Zimbabwe Rapid Impact Needs Assessment, Vol. 24. https://doi.org/10.1044/leader.ppl.24052019.24. Accessed 2 Aug 2020.

Saunders, M.N.K., P. Lewis, and A. Thornhill. 2019. Research methods for business students. New York: Pearson.

Sedgwick, P. 2015. Units of sampling, observation, and analysis. British Medical Journal 351: Article h5396.

Slovic, P. 2001. The risk game. Journal of Hazardous Materials 86: $17-24$.

Torani, S., P.M. Majd, S.S. Maroufi, M. Dowlatiand, and R.A. Sheikhi. 2019. The importance of education on disasters and emergencies: A review article. Journal of Education Health Promotion 8: Article 85.

UNICEF (United Nations Children's Fund). 2019. Zimbabwe Cyclone Idai situation report No. 2, 15-24 March 2019. Harare, Zimbabwe: United Nations Children's Fund.

Wamukonya, N., and H. Rukato. 2001.Climate change implications for Southern Africa. http://www.energia.org/fileadmin/files/ media/pubs/wamukonyarukato.pdf. Accessed 23 Sept 2020.

World Bank. 2019. Project Information Document (PID). Report No. PIDA27189. Washington, DC: World Bank. 